\title{
LEARNER ATTRITION IN AN ADVANCED VOCATIONAL ONLINE TRAINING: THE ROLE OF COMPUTER ATTITUDE, COMPUTER ANXIETY, AND ONLINE LEARNING EXPERIENCE
}

\author{
Klaus D.Stiller[klaus.stiller@ur.de],Department of Pedagogy,University of Regensburg, \\ Annamaria Köster [koester.annamaria@gmail.com], University of Duisburg-Essen, Germany
}

\begin{abstract}
Online learning has gained importance in education over the last 20 years, but the well-known problem of high dropout rates still persists. According to the multi-dimensional learning tasks model, the cognitive (over)load of learners is essential to attrition when dealing with five challenges (e.g. technology, user interface) of an online training (Tyler-Smith, 2006). The experienced load might depend on learner characteristics. The study explored the extent that learners dropping out from a vocational video-based online training about media design for employees of micro, small and medium-sized enterprises differ from working learners' online learning experience, computer attitude, and computer anxiety. The data were collected from 72 of 128 registered employees who completed a questionnaire before starting the course to analyze differences between the dropout group (submitted no solutions to online training tasks; $\mathrm{n}=19$ ) and the active learner group (submitted at least one of 13 task solutions; $n=53$ ). No differences were found in online learning experience, but the dropout group reported more negative attitudes towards computers and a higher level of computer anxiety than the active learner group.
\end{abstract}

\section{Abstract in German}

In den vergangenen 20 Jahren ist Online-Lernen immer wichtiger für den Bildungssektor geworden. Trotzdem besteht immer noch das bekannte Problem hoher Abbruchquoten bei Onlinekursen. Gemäß dem Modell der multidimensionalen Lernaufgaben (multi-dimensional learning tasks model) (Tylor-Smith, 2006) ist der cognitive (over)load des Arbeitsgedächtnisses der Lernenden, welchen diese während der Auseinandersetzung mit fünf Herausforderungen bei Onlinekursen (z.B. Technologie und Benutzerinterface) erleben, maßgeblich für den Kursabbruch. Es ist anzunehmen, dass der cognitive load des Arbeitsgedächtnisses auch von Lernermerkmalen abhängt. Im Rahmen eines videobasierten Online-Weiterbildungskurses für Mitarbeiterinnen und Mitarbeiter kleinster, kleiner und mittlerer Unternehmen zum Erwerb von Kenntnissen und Fertigkeiten in Mediengestaltung wurde untersucht, inwiefern sich Kursabbrecher von anderen Lernenden unterscheiden. Betrachtet wurde ihre Vorerfahrung im Online-Lernen, Einstellung zum Computer und Computerängstlichkeit. Hierfür wurde vor dem Kursstart an 128 für die Weiterbildung registrierte Personen ein Fragebogen versandt, welcher von 19 späteren Kursabbrechern und 53 Lernenden beantwortet wurde. Abbrecher wurden darüber operationalisiert, dass sie zu keinerlei Aufgaben der Weiterbildung Bearbeitungen eingereicht haben, während die Lernenden zumindest eine Aufgabenlösung zu insgesamt 13 möglichen Aufgaben abgaben. Es zeigten sich keine Unterschiede in der Vorerfahrung im Online-Lernen, jedoch berichtete die Gruppe der Abbrecher negativere Einstellungen gegenüber dem Computer und ein höheres Niveau an Computerängstlichkeit als die Gruppe der Lernenden.

Keywords: dropout, computer attitude, computer anxiety, online learning experience, cognitive load theory 


\section{Introduction}

Online learning has gained importance in higher education and (advanced) vocational training over the last 20 years (e.g., Allen \& Seaman, 2010, 2015; Myers \& Schlitz, 2012), especially because the new technologies are suggested to fit the needs of adult learners (Lakhal \& Bazinet, 2015) who can freely decide which contents they work through, where and when they work, and for how long they work. Online courses in higher education also seem to be at least as efficient as face-to-face courses (Bernard et al., 2004a; U.S. Department of Education, 2010), but the problem of high dropout rates has not been solved to date (Herbert, 2006; Levy, 2007). Dropout rates between 50 to 70\% are regularly reported (Kranzow, 2013; Xenos et al., 2002). The lowest reported rates are $20 \%$ and the highest are $80 \%$. These and other results clearly demonstrate the existence of an attrition problem.

Generally, dropout is a complex phenomenon and seems to be dependent on various learner characteristics and other factors. Online student dropout has been described and analysed in the contexts of whole study programs (e.g., Grau-Valldosera \& Minguillón, 2014) and single online courses (e.g., Lee \& Choi, 2011), but the dropout definitions provided in these investigations have been heterogeneous, not clearly explained or not provided at all (Lee \& Choi, 2011; TylerSmith, 2006). In the context of single online courses, for example, one reason for the equivocality is that dropout can occur in several moments while participating in a course. The basis could be the number of registered participants who present numerous possibilities for dropping out of the course, for example, when they fail to start learning, are completely inactive, fail to submit solutions to learning tasks, are not granted permission to take the exam, fail to take the exam or do not pass the exam (Fritsch \& Ströhlein, 1988). The heterogeneity of dropout operational definitions is well depicted by the examples provided by Lee and Choi (2011). Furthermore, the types of online courses vary widely (Tyler-Smith, 2006). Determinants of learner attrition and persistence with online training have been shaped in various models with different levels of complexity (e.g., Ajzen, 1991; Gazza \& Hunker, 2014; Kember, 1989; Lee \& Choi, 2011; Park, 2007; Rovai, 2003; Tinto, 1993). In their review of online course dropout research in postsecondary education, Lee and Choi (2011) identified 69 factors influencing dropout, which were clustered in three main categories bearing nine sub-factors: (a) Student factors (academic background, relevant experiences, relevant skills, and psychological attributes), (b) Course/Program factors (course design, institutional supports, and interactions), and (c) Environmental factors (work commitments and supportive study environments). This comprehensive organization clearly demonstrates the complexity of the dropout issue.

In this study, we focussed on student factors, more precisely, on the psychological attributes of computer attitude and computer anxiety and on relevant online learning experiences based on cognitive load theory (CLT) (Sweller, 2010). We explored the extent that learners dropping out from a vocational video-based online training course about media design for employees of micro, small and medium-sized enterprises differ from active learners on the three student characteristics. The theoretical part of this article first describes the multi-dimensional learning tasks model (MDLTM) (Tyler-Smith, 2006), which explains attrition according to cognitive load theory, followed by a characterization of the concepts of online learning experience, computer attitude and computer anxiety against that background. 


\section{Theoretical framework}

\section{The multi-dimensional learning tasks model and the cognitive load theory}

The MDLTM proposes five challenges (tasks) that learners must deal with successfully to engage in an online course: (a) negotiating the technology, (b) negotiating the Learner Management System interface, (c) negotiating the learner role (this term replaces the original term becoming an eLearner), (d) negotiating the learning content, and (e) negotiating Computer Mediated Communication interaction. Tyler-Smith (2006) based his explanations of how these challenges contribute to early attrition in an online course on cognitive load theory. Therefore, we first describe CLT briefly and then discuss the MDLTM.

CLT emphasizes the role of the working memory in learning and the problem of occupying working memory by useful und unnecessary cognitive processes, that is, cognitive loads (Sweller, 2010). The cognitive processes that are executed in working memory are thought to determine the effectiveness of learning. Only when information processing occurs without disturbances can learners build an adequate mental representation that will be stored effectively in long-term memory. A working memory with limited capacity only allows processing of a few information elements at a time. If rehearsal of memory items is not possible, items fade within seconds. Learning complex tasks is often difficult because of the limitations of working memory. Learners must hold numerous elements (e.g. rules, states, etc.) in working memory while relating them, which often exceeds working memory capacity. The components of cognitive load are intrinsic, germane and extraneous loads. Intrinsic load is created by task complexity; it is the basic amount of processing required for understanding a presentation. Germane load goes beyond understanding and is bound to processing information used to build schemas and store them in long-term memory. Extraneous load results from the presentation manner of the material and is often the main source that inhibits learning, because it is unrelated to the construction or automation of schemas. Successful learning occurs when working memory capacity is not overburdened by overall cognitive load and when as much capacity as is available can be dedicated to schema acquisition and automation, which creates germane load. Cognitive overload is mostly created by extraneous and intrinsic load.

The MDLTM focuses on the cognitive load imposed by solving various core tasks that are crucial to the learner's course persistence. When cognitive overload occurs, learners are more likely to drop out from the course. The MDLTM was developed for first-time online learners who must deal with the core tasks immediately and simultaneously, but it could also be considered for any learner who might be unfamiliar with the specific requirements of any course environment. In the first task, negotiating the technology, the learner must cope with the range of technologies used in a course. This challenge might require learners to acquire new or to improve their available skills, for example, learning about hardware or software, installing and configuring it. The second task, negotiating the Learner Management System interface, requires the learner to build an adequate model of the course structure and navigation. The usability of an online course environment is suggested to be a very important aspect for a learner's success or failure in negotiation. The core element of the third task, negotiating the learner role, is to accept the role a learner is required to play in an online course. For example, learners are often expected to be self-directed, motivated, and they are assumed to be physically isolated from instructors and other learners. If learners, however, would rather be in the common role of a learner attending a class instructed by a teacher in front, this might contribute to the high dropout rates of online courses. Negotiating the learning content is the fourth task, which refers to the learning materials in and didactics of the online course and is related to the ability to engage in and to master the required activities (with a particularly focus on adequate cognitive processing) in the course. Learners' confidence and ability to manage the 
content might depend on their learning experience, prior domain-specific knowledge, and available learning strategies. The fifth task, negotiating CMC interaction, focusses on the synchronous and asynchronous channels of communication in the online course and is related to the ability to engage in and master the required communicative activities. Often, communication is based on electronic texts and special structures (e.g. discussion forums) that might not be familiar to all learners. The learner's confidence and ability to manage communication might depend on the learner's experience with special kinds of communication channels and available communication strategies.

\section{Learner characteristics influencing learner attrition in online courses}

Attitudes consist of affective, conative and cognitive components. This article focuses on the cognitive component of computer attitudes, which underlies the Questionnaire for the Contentspecific Assessment of Attitudes toward the Computer (Richter et al., 2000, 2010). In this context, attitudes are defined as beliefs that are organized in topics. The topic of interest was the computer as an object of personal experience, and the computer as an instrument for working and learning was the subtopic. Moreover, attitudes towards computers are assumed to reflect a bipolar structure. A person might concurrently have negative and positive beliefs about the same point. Computer attitude is a learner feature that might influence a learner's decision to drop out by affecting working memory load. Negative computer attitudes might engender a more extraneous load particularly while negotiating both the technology and the Learner Management System interface because of, for example, disturbing thoughts about the computer malfunctioning or even crashing. Learners with positive attitudes should be less prone to such thoughts and thus less likely to suffer from extra working memory load by task-foreign cognitions. Consequently, learners are assumed to engage adequately in negotiating technology and system interface. Some characteristics of online learning courses might especially be prone to activate computer attitudes and arouse disturbing thoughts, for example, the type of navigation or the type of presentation (e.g. using videos). The activation of computer attitudes is not assumed to be directly affected by design characteristics but rather on the perceived technical complexity. Learners judge the technical complexity of an instruction on the basis of their beliefs about the technical demands of the perceived instructional functions and features. A complex type of navigation or using audio and video, for example, might be judged to be technically complex and therefore error-prone. Hence, computer attitudes are likely to be activated, which in turn will increase extraneous load and thus initiate a dropout decision when attitudes are negative. Only a few studies have been conducted on the effects of computer attitudes on learning performance and have found negative effects of negative attitudes and interaction effects with information presentation and navigation (Stiller, 2009, 2015), and also positive effects of positive attitudes (e.g., attitudes towards e-learning, internet use, information technology, or technology use) on course usage and persistence were evidenced (e.g., Bernard et al., 2004b). To date, most studies have focused on their relationships to computer knowledge and computer usage (Richter et al., 2010; Sam et al., 2005).

Similar to the perspective on computer attitudes and online learning, computer anxiety is also a learner feature that might influence learning with computers by affecting working memory load. Computer anxiety is considered to be a trait, which comprises both cognitive and affective components such as feelings of anxiety and worrisome thoughts (Richter et al., 2010). Computer anxiety might engender a more extraneous load because of coping with negative emotions and negative thoughts about the computer. In contrast, learners without computer anxiety are less likely to suffer from extra working memory load. Consequently, learners are assumed to adequately engage in negotiating both the technology and the Learner Management System interface. To date, most studies have focused on the relationships between anxiety, computer 
self-efficacy, and performance or learning system usage (also computer usage), mostly assuming that anxiety has only an indirect negative effect on performance and course usage but has a direct influence on self-efficacy which directly influences performance and course usage (Hauser et al. 2012; Saadé \& Kira, 2009; Sam et al., 2005). Few studies have investigated computer anxiety and course dropout or course persistence (e.g., Long et al., 2009). Long et al. (2009) presented no differences between employees of a Midwest-based landscaping company in the U.S. who completed an online course and dropping out.

The learner's experience with online learning might also affect working memory load while learning. Online learning experience could comprise various aspects that accompany participation in online learning courses such as knowledge about online learning portals and their usage, typical course processes, and adequate learning strategies. From this point of view, having some online learning experience could help a learner expend less working memory resources, for example, on the correct usage of an online portal, when to do what action in the course progression and how to perform an efficient learning action. Hence more experienced learners could concentrate more on learning than less experienced learners. In particular, good design and usability are important in the face of low experience with online training. Ample evidence exists in the literature showing positive effects of online learning experience on performance and course persistence (e.g., Dodd et al., 2009; Hachey et al., 2014; Lee \& Choi 2011; Park \& Choi, 2009; Sam et al., 2005).

\section{Research questions}

We examined whether learner attrition in an online advanced vocational training is influenced by online learning experience, computer attitude, and computer anxiety by simply comparing a group of learners who dropped out and a group of learners who worked on course modules in respect of the learner characteristics. We expected that the dropout group would have less online learning experience, more negative attitudes and a higher level of computer anxiety compared to the group of working learners.

We assumed that dropout is more likely when a learner has more negative attitudes towards computers, a higher level of computer anxiety, and a lower level of experience in online learning (see Figure 1). In particular, negative attitudes towards computers and higher computer anxiety are expected to contribute to a higher level of extraneous load because of task irrelevant cognitions and emotions triggered by online learning, especially while negotiating the technology and negotiating the Learner Management System interface. When high extraneous load compromises working memory, the learner is expected to experience a low self-efficacy and as a result drop out of the course. Correspondingly, a low level of online learning experience was expected to result in a higher level of extraneous load because of the lack of schemas for online learning environments, especially while negotiating the Learner Management System interface, and also because of a lack of knowledge about learning with videos, particularly while negotiating the learning content. Again, when extraneous load is too high, the learner is expected to experience a low self-efficacy and consequently drop out of the course. 
Positive learner characteristics and dropout

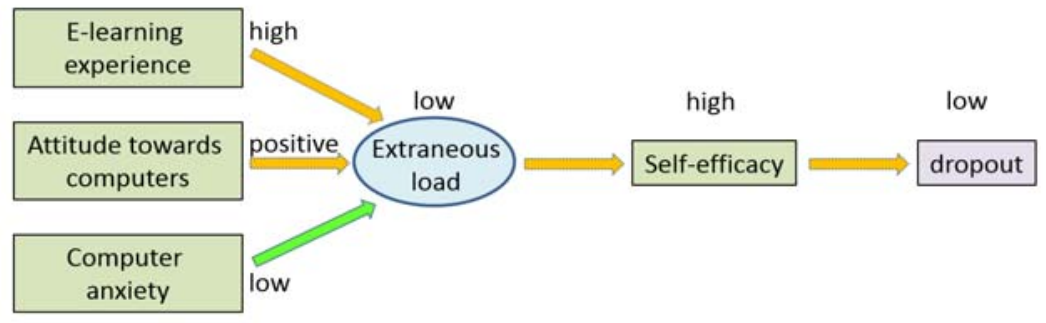

Negative learner characteristics and dropout

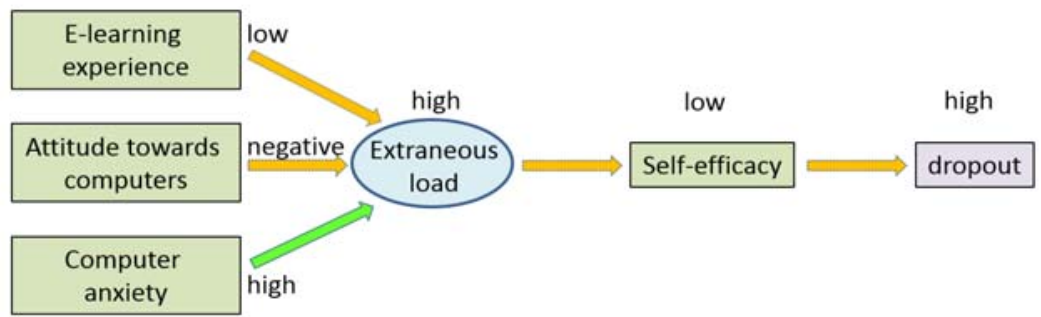

Figure 1. Paths illustrating the effects of learner characteristics (left) on extraneous load and the effects of extraneous load on self-efficacy and on dropout. Green arrows indicate positive correlations and orange arrows indicate negative correlations.

\section{Method}

Refer to Stiller and Bachmaier (2014) to receive further information about the online training course used in this study, methods, and the evaluative descriptive results.

\section{Research subjects}

The data was collected from the students who registered for the online training NiceDesign4SME (Nice Design for Small and Medium-sized Enterprises). The training contributes to the field of continuing vocational education and training on media design and mainly addresses employees of any position from micro, small or medium-sized enterprises of any kind. Students were recruited by promoting the online training NiceDesign 4 SME online on various relevant message boards and pages (including press releases) and offline via flyers. Additionally, in the development of the online training, some enterprises were obtained that provided support for employees to participate in the NiceDesign4SME training. Promotion mainly focussed on the German Federal State of Bayern. The sample of employees is regarded to be representative of the NiceDesign4SME target group.

One hundred and twenty-eight employees signed up for the course. All employees who registered for the course $(n=128)$ were sent a questionnaire one week before training started. Twenty-six of these participants never logged into the online training and only two of them completed the questionnaire, thus they were excluded from analyses. This group was named absent participants. The remaining 102 employees were divided into two groups: A dropout group of 44 employees and a learner group of 58 employees. In this study, dropout was operationalized as learners showing only minimal activity, that is, logging in at least once but not having worked on any online training tasks. Correspondingly, learners were identified as having worked on at least one module task. From the 102 employees, 19 qualified as dropouts and 53 as learners (see Table 1). The learner group had a higher return rate than the dropout group ( $91 \%$ vs. $43 \%)$. More female than male employees participated in the training. The mean age of employees was 38 years 
$(\mathrm{SD}=12$, range from 18 to 68 years, $\mathrm{n}=71)$. Most employees $(94.4 \%)$ had a post-secondary school diploma, a secondary school or commercial college certificate or an entrance qualification for universities for applied sciences. The size of the enterprises spread from one-man enterprises to large enterprises having more than 250 employees, but most enterprises were micro enterprises having less than 10 employees (69\%). The most reported branches were freelance, economic or technical services $(n=14)$, information and communication $(n=11)$, and health and social services $(\mathrm{n}=8)$.

Table 1: The demographic characteristics of the registered student employees

\begin{tabular}{|c|c|c|c|c|}
\hline & $\begin{array}{l}\text { No. }(\%) \text { of } \\
\text { registered } \\
\text { participants }\end{array}$ & $\begin{array}{l}\text { No. }(\%) \text { of absent } \\
\text { participants }\end{array}$ & $\begin{array}{l}\text { No. (\%) of } \\
\text { dropout } \\
\text { participants }\end{array}$ & $\begin{array}{l}\text { No. }(\%) \text { of } \\
\text { studying } \\
\text { participants }\end{array}$ \\
\hline Total & $128(100)$ & $26(20.3)$ & $44(34.4)$ & $58(45.3)$ \\
\hline \multicolumn{5}{|l|}{ Sex } \\
\hline female & $90(70.3)$ & $18(69.2)$ & 29 (65.9) & 44 (75.9) \\
\hline male & $38(29.7)$ & $8(30.8)$ & $15(34.1)$ & $14(24.1)$ \\
\hline \multicolumn{5}{|l|}{ No. of completed modules } \\
\hline 0 & $71(55.5)$ & $26(100)$ & $44(100)$ & $1(1.7)$ \\
\hline $1-3$ & $17(13.3)$ & & & $17(29.3)$ \\
\hline 4-7 & $4(3.1)$ & & & $4(6.9)$ \\
\hline \multicolumn{5}{|l|}{$8-9$} \\
\hline 10 & $4(3.1)$ & & & $4(6.9)$ \\
\hline $11-13$ & $32(25.0)$ & & & $32(55.2)$ \\
\hline Returned questionnaires & $74(57.8)$ & $2(7.7)$ & $19(43.2)$ & $53(91.4)$ \\
\hline \multicolumn{5}{|l|}{ Sex } \\
\hline female & $55(74.3)$ & $1(50)$ & $13(68.4)$ & $41(77.4)$ \\
\hline male & $19(25.7)$ & $1(50)$ & $6(31.6)$ & $12(22.6)$ \\
\hline \multicolumn{5}{|l|}{ Age } \\
\hline Missing values & $1(1.4)$ & & $1(5.3)$ & \\
\hline$<20$ & $3(4.1)$ & & & $3(5.7)$ \\
\hline $20-29$ & $20(27.0)$ & & $3(15.8)$ & $17(32.1)$ \\
\hline 30-39 & $17(23.0)$ & $1(50)$ & $4(21.1)$ & $12(22.6)$ \\
\hline $40-49$ & $20(27.0)$ & & $8(42.1)$ & $12(22.6)$ \\
\hline $50+$ & $13(17.6)$ & $1(50)$ & $3(15.8)$ & $9(17.0)$ \\
\hline \multicolumn{5}{|l|}{ Educational level } \\
\hline graduation other than listed & $2(2.7)$ & & & $2(3.8)$ \\
\hline $\begin{array}{l}\text { secondary modern school- } \\
\text { leaving certificate }\end{array}$ & $4(5.4)$ & & $1(5.3)$ & $3(5.7)$ \\
\hline $\begin{array}{l}\text { secondary school or } \\
\text { commercial college } \\
\text { certificate }\end{array}$ & $23(31.1)$ & $1(50)$ & $6(31.6)$ & $16(30.2)$ \\
\hline $\begin{array}{l}\text { entrance qualification for } \\
\text { universities for applied } \\
\text { sciences }\end{array}$ & $9(12.2)$ & & $2(10.5)$ & $7(13.2)$ \\
\hline $\begin{array}{l}\text { post-secondary school } \\
\text { diploma }\end{array}$ & $36(48.6)$ & $1(50)$ & $10(52.6)$ & $25(47.2)$ \\
\hline \multicolumn{5}{|l|}{ Size of enterprises } \\
\hline 1 employee & $19(25.7)$ & & $7(36.8)$ & $12(22.6)$ \\
\hline 2-9 employees & 31 (41.9) & $2(100)$ & $9(47.4)$ & $20(37.7)$ \\
\hline 10-49 employees & $10(13.5)$ & & $2(10.5)$ & $8(15.1)$ \\
\hline 50-99 employees & $4(0.1)$ & & & $4(7.5)$ \\
\hline $100-250$ employees & $2(0.0)$ & & & $2(3.8)$ \\
\hline$>250$ employees & $8(10.8)$ & & $1(5.3)$ & $7(13.2)$ \\
\hline
\end{tabular}




\section{Description of the online training course NiceDesign4SME}

NiceDesign4SME is exclusively an online training course without a fixed schedule that uses asynchronous tools for communication between learners and tutors and among learners. It consists of 13 modules, organized in four blocks (graphics and colour: image design, image processing, and logo design; print media: typographical basics, business letter, designing flyers and posters; digital presentations: presentation according to Zen, social media, content strategy, and content management systems; general basics: how to write, open source, and legal basics). The core element of each module is an instructional video lasting about 15 minutes. Videos are supplemented by a pool of learning material learners can use for further elaboration of the contents. Learners are asked to complete different module tasks to construct knowledge. For each module the evaluation and feedback for the module task solutions was given by the module expert. Employees who worked through all modules and had successfully solved 11 of the 13 module tasks received a training completion certificate. The expected workload to successfully complete the training was 20 to 25 hours. In addition, an introductory module informed the employees about the content, technical requirements and course organization.

The framework of NiceDesign4SME was constructed around the five design principles of problem-based learning environments (Reinmann \& Mandl, 2006): learning situated in authentic problems; using multiple contexts for learning; using multiple perspectives for learning; learning in a social context; and learning with instructional support. In addition, the structure of each module was modelled on the Nine Events of Instruction (Gagné et al., 1992). When preparing the design of the learning environment and the instructional materials, we paid particular attention to providing a high level of self-instruction (Rowntree, 1998) and an effective and efficient information presentation (Sweller, 2010).

The starting point is a Moodle course portal. The module pages are composed of three sections (see Figure 2):

1. The course details provide information about the module's tutor and the student (if added), and an overview of the student's learning performances of the modules.

2. The content area comprises the following six parts:

- The module profile provides an overview of the content and the teaching objectives.

- The videos present the contents in a didactically-designed way.

- Links to external resources and literature that could be used for further elaboration are presented in the supplements section.

- The training task is used for controlling whether the module objectives were reached by the learners. Some modules provide transfer tasks and others a set of multiplechoice questions.

- The support section provides access to an internal message board, which could be used when learners had questions about contents or difficulties in understanding a module task or solving a problem.

- The media presentation section enables learners to provide access to their media products. The purpose was to generate discussion and receive feedback from tutors and other learners.

3. The navigation area provides an overview of the module's content and direct access to all content sections. 
The videos follow a common routine. First, a moderator introduces the module and then the video transitions to focus on the meaning of the module title. The content includes a typical real world problem, exemplified by an employee of an enterprise who attempts to solve it according to clearly formulated goals. The components of the solution procedure are presented to the learner in sequence. Components could be design standards and rules and actions that demonstrate them. Knowledge of design is utilized and skills used to produce results. Finally, the moderator reappears and concludes the video.

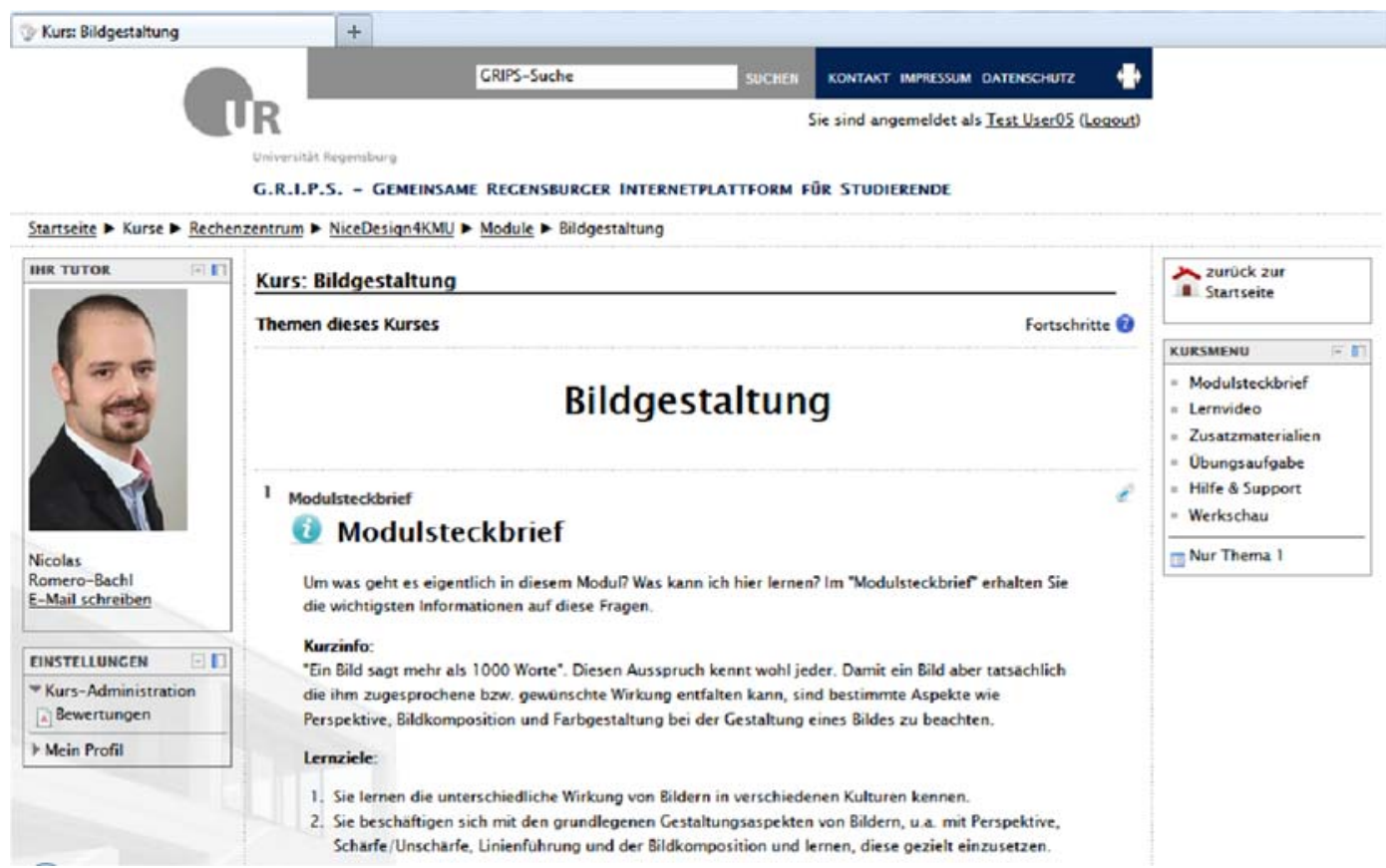

Figure 2. Screenshot of the "image design" module. Left: Listing of the course details. Central: The module's content area. Right: Navigation tools.

\section{Procedure and means of measurements}

One week before starting the training, the employees received an invitation to an online questionnaire via email. The employees were first asked about their age, sex, level of education, and the size and sector of the enterprise in which they work. They then rated their experience with online training and instructional videos. Subsequently, their attitude towards computers was assessed. The questionnaire focuses on the personal experience with using the computer as a means for learning and working (Richter et al., 2000, 2010). The negative component of the attitude (i.e., the computer is regarded as an uncontrollable machine) was measured by seven statements. A high score indicated a low negative attitude. Afterwards, computer anxiety was measured by eight statements referring to the cognitive and affective components (Richter et al., 2000, 2010). Table 2 shows the items used for measuring employees' e-learning experience, computer attitude and computer anxiety. Participants' scores were calculated as the means of the item scores. Scale features are presented in Table 3. After starting the course, employees had 12 weeks to work on 13 modules. 
Table 2: Items measuring e-learning experience, computer attitude and computer anxiety.

\begin{tabular}{|c|c|}
\hline & $\begin{array}{l}\text { arning experience items were rated on five-point Likert scales from "no experience" to "a lot of } \\
\text { rience" (1) and "never" to "very often" (2). }\end{array}$ \\
\hline 1 & How much experience do you have with online training? \\
\hline 2 & Have you ever used instructional videos for learning (e.g., from YouTube or CD)? \\
\hline & $\begin{array}{l}\text { iputer attitude items were rated on five-point Likert scale from "do not agree" to "agree" (scale } \\
\text { sonal experience / learning and working / autonomous entity" by Richter et al., 2000). }\end{array}$ \\
\hline 1 & To me, the computer seems too unreliable to use as a learning tool. \\
\hline 2 & $\begin{array}{l}\text { I am often frustrated by the fact that the computer simply does not make sense to ordinary } \\
\text { people. }\end{array}$ \\
\hline 3 & When I use the computer for work, I constantly worry that it might break down. \\
\hline 4 & Working with the computer is often frustrating because I do not understand the machine. \\
\hline 5 & Sometimes my computer does things I do not understand. \\
\hline 6 & When I work with a computer, I feel that the computer does what it wants. \\
\hline 7 & If I have computer problems while I am working, I feel helpless. \\
\hline & $\begin{array}{l}\text { iputer anxiety items were rated on five-point Likert scale from "do not agree" to "agree" (scale } \\
\text { nfidence in dealing with computers and computer applications" by Richter et al., 2010). }\end{array}$ \\
\hline 1 & I feel confident in using the computer. \\
\hline 2 & I panic when my computer crashes. \\
\hline 3 & In working with the computer, I am easily frustrated when problems occur. \\
\hline 4 & Working with the computer makes me uneasy. \\
\hline 5 & When working with the computer, I am often worried that I might break something. \\
\hline 6 & I feel that I cannot really control my computer. \\
\hline 7 & If possible, I avoid working with the computer. \\
\hline 8 & In the case of occurring computer problems, I stay calm. \\
\hline
\end{tabular}

Table 3: Descriptive statistics and Pearson correlation coefficients of e-learning experience items and Cronbach's alpha of the computer scales $(n=74)$

\begin{tabular}{lcccccc}
\hline & Items & $\mathrm{M}$ & $\mathrm{SD}$ & Range & Alpha & Correlation \\
\hline E-learning experience & 2 & .98 & 1.06 & $0-4$ & & .60 \\
Computer attitude & 7 & 4.32 & .62 & $1-5$ & .79 & \\
Computer anxiety & 8 & 1.66 & .42 & $1-5$ & .66 & \\
\hline
\end{tabular}

\section{Results}

Before analysing the differences between the dropout and the learner groups in online learning experience, computer attitude and computer anxiety, the groups were compared across sex, age, level of education and size of enterprise to test whether groups were confounded with these learner features. Otherwise, differences in online learning experience, computer attitude and computer anxiety between groups might be misinterpreted. Table 4 shows the results of the analyses. No differences were found between the dropout and learner groups on all demographic variables. For the analysis of level of education, the categories post-secondary school diploma and an entrance qualification for universities for applied sciences formed the group of higher educational level, and the secondary school or commercial college certificate, a secondary modern school-leaving certificate and a graduation from a school other than those listed formed the group of lower educational level. Two groups were formed for the enterprise size analysis: enterprises of 1-9 employees (micro enterprises) and enterprises of more than nine employees (small, medium- and big-sized enterprises). 
Table 4: Descriptive statistics, test results, and effect sizes of the dropout and learner group demographic variables

\begin{tabular}{lcccccccc}
\hline & \multicolumn{9}{c}{ Dropouts } & \multicolumn{2}{c}{ Learners } & & & & \\
& $\mathrm{M}$ & $\mathrm{SD}$ & $\mathrm{M}$ & $\mathrm{SD}$ & Welch-t & $\mathrm{df}$ & $\mathrm{p}$ & $\mathrm{d}$ \\
\hline Age & 36.8 & 12.8 & 40.4 & 11.0 & 1.18 & 32.74 & $\mathrm{~ns}$ & .31 \\
& Female & Male & Female & Male & Chi-square* & & & \\
Sex & 13 & 6 & 41 & 12 & .60 & 1 & $\mathrm{~ns}$ & .18 \\
& Low & High & Low & High & Chi-square & & & \\
Level of education & 7 & 12 & 21 & 32 & .05 & 1 & $\mathrm{~ns}$ & .05 \\
& Small & Big & Small & Big & Chi-square* & & & \\
Size of enterprise & 16 & 3 & 32 & 21 & 3.57 & 1 & ns & .46 \\
\hline
\end{tabular}

Note: Effect size $d$ for Chi-square tests were calculated from the Chi-square-value (see Elis, 2010). Chi-square tests marked with * were verified by Fisher's exact test, because in one cell the frequency expected value was $<5$.

Finally, no difference was found between the dropout and the learner group in online learning experience, but the attitudes of the dropout group were more negative, and they reported a higher level of computer anxiety. Table 4 shows the descriptive statistics of the dropout and learner groups as well as the results of the calculated one-sided Welch-tests.

Table 5: Means and standard deviations of the dropout and learner groups, Welch-test results and effect sizes on online learning experience, computer attitude and computer anxiety.

\begin{tabular}{lcccccccc}
\hline & \multicolumn{2}{c}{ Dropouts } & \multicolumn{2}{c}{ Learners } & & & & \\
& $\mathrm{M}$ & $\mathrm{SD}$ & $\mathrm{M}$ & $\mathrm{SD}$ & Welch-t & $\mathrm{df}$ & $\mathrm{p}$ & $\mathrm{d}$ \\
\hline Online learning experience & 1.18 & .84 & 1.28 & 1.13 & -.40 & 42.83 & $\mathrm{~ns}$ & -.09 \\
Computer attitude & 3.98 & .66 & 4.34 & .53 & -2.11 & 26.54 & .02 & -.64 \\
Computer anxiety & 1.99 & .51 & 1.65 & .37 & 2.68 & 25.07 & .01 & .83 \\
\hline
\end{tabular}

\section{Discussion}

Online learning experience was not indicative of dropping out. One reason for the null finding could be that the operationalization of online learning experience does not provide sufficient information about the learner's prior training experience. The extent of an employee's experience with online training should be supplemented with items that assess prior online course outcomes. Hachey et al. (2014) showed that prior online course outcomes of college students are a good predictor for dropout and learning success. In other words, negative outcomes can predict future negative outcomes, and positive outcomes can predict future positive outcomes (Hachey et al., 2014). This aspect was neglected in the present study.

The learner characteristics of computer attitude and computer anxiety were found to contribute to dropping out. Learners dropping out from the video-based online training had higher levels of computer anxiety and more negative attitudes towards the computers. These results are in line with evidence from other studies (Hauser et al. 2012; Saadé \& Kira, 2009). We should note that employees had a very positive attitude towards computers and were widely free of computer anxiety as indicated by the scores being relatively high for computer attitude and low for computer anxiety. Thus, employees who dropped out reported no extreme anxiety of computers or negative attitude towards them. They only reported a little more anxiety and slightly more negative attitudes than learners. Viewing the results from this perspective, the significant differences between the dropout and learner groups is quite surprising. 
Why were the employees widely free of negative attitudes towards computers and computer anxiety? A possible explanation could be that the student employees in the online training target group were enrolled in advanced vocational training in media design, which requires extensive use of computers. A reasonable assumption is that these type of students are familiar with and very fond of computers. In other contexts, people's computer anxiety and computer attitudes are likely to vary more. In such contexts, the higher variability of characteristics might better explain dropping out than in this study. Moreover, dropping out in this study was correlated with the return rate of the questionnaire. The response rate of the learner group was high, but the low response rate of dropouts suggests that the non-responders who could not be assessed would have reported more negative attitudes towards computers and higher computer anxiety.

Future studies should focus on when dropping out occurs and the reasons according to the MDLTM. Investigating the extent that dropping out occurs as a result of cognitive overload is essential and, according to the theory, how overload might contribute to lower levels of selfefficacy, which is directly connected to dropping out (Hauser et al. 2012; Saadé \& Kira, 2009). In this study, we showed that the two learner characteristics of negative attitudes toward computers and anxiety are connected to dropping out. We expect that these characteristics influence cognitive load, but we did not test that assumption. Future studies should also expand the analyses to other factors that lie outside the online learning experience such as family circumstances and health, particularly for advanced vocational training. Expanding the list of learner characteristics that are easy to assess can lead to more effective interventions to increase persistence and successful training outcomes.

\section{References}

1. Allen, I. E., \& Seaman, J. (2010). Learning on Demand. Online Education in the United States, 2009. Babson Park, MA: Babson Research Group.

2. Allen, I. E., \& Seaman, J. (2015). Grade level: Tracking online education in the United States. Babson Park, MA: Babson Research Group.

3. Ajzen, I. (1991). The theory of planned behaviour. Organizational Behavior and Human Decision Processes, 50, 179-211.

4. Bernard, R. M., Abrami, P. C., Lou, Y., Borokhovski, E., Wade, A., Wozney, L., Wallet, P. A., Fiset, M., \& Euan, B. (2004a). How does distance education compare with classroom instruction? A meta-analysis of the empirical literature. Review of Educational Research, 74(3), 379-439.

5. Bernard, R. M., Brauer, A., Abrami, P. C., \& Surkes, M. (2004b). The development of a questionnaire for predicting online learning achievement. Distance Education, 25(1), 31-47.

6. Dodd, C., Kirby, D., Seifert, T., \& Sharpe, D. (2009). The impact of high school distance e-learning experience on rural students' university achievement and persistence. Online Journal of Distance Learning Administration, 12(1). Retrieved from http://www.westga.edu/ distance/ojdla/spring121/dodd121.html

7. Elis, P. (2010). The essential guide to effect sizes: Statistical power, meta-analysis, and the interpretation of research results. Cambridge: Cambridge University Press.

8. Fritsch, H. \& Ströhlein, G. (1988). Mentor support and academic achievement. Open Learning, $3(2), 27-32$. 
9. Gagné, R. M., Briggs, L. J., \& Wager, W. W. (1992). Principles of instructional design. Belmont, CA: Wadsworth/Thomson Learning.

10. Gazza, E. A., \& Hunker, D. F. (2014). Facilitating student retention in online graduate nursing education programs: A review of the literature. Nurse Education Today, 34(7), 11251129.

11. Grau-Valldosera, J., \& Minguillón, J. (2014). Rethinking dropout in online higher education: The case of the Universitat Oberta de Catalunya. The International Review of Research in Open and Distributed Learning, 15(1), 290-308.

12. Hauser, R., Paul, R., \& Bradley, J. (2012). Computer self-efficacy, anxiety, and learning in online versus face to face medium. Journal of Information Technology Education: Research, 11, 141154.

13. Hachey, A. C., Wladis, C. W., \& Conway, K. M. (2014). Do prior online course outcomes provide more information than G.P.A. alone in predicting subsequent online course grades and retention? An observational study at an urban community college. Computers \& Education, 72, 59-67.

14. Herbert, M. (2006). Staying the course: A study in online student satisfaction and retention. Online Journal of Distance Learning Administration, 9(4). Retrieved March 3, 2016, from http://www.westga.edu/ distance/ojdla/winter94/herbert94.htm

15. Kember, D. (1989). A longitudinal-process model of drop-out from distance education. Journal of Higher Education, 60(3), 278-301.

16. Kranzow, J. (2013). Faculty leadership in online education: Structuring courses to impact student satisfaction and persistence. Journal of Online Learning and Teaching, 9(1), 131-139.

17. Lakhal, S., \& Bazinet, N. (2015). Technological factors explaining student dropout from online courses in higher education: A review. In S. Carliner, C. Fulford \& N. Ostashewski (Eds.), Proceedings of EdMedia: World Conference on Educational Media and Technology 2015 (pp. 1806-1811). Chesapeake, VA: AACE. Retrieved from http://www.editlib.org/p/151456/

18. Lee, Y., \& Choi, J. (2011). A review of online course dropout research: Implications for practice and future research. Educational Technology Research and Development, 59(5), 593-618.

19. Levy, Y. (2007). Comparing dropouts and persistence in e-learning courses. Computers \& Education, 48(2), 185-204.

20. Long, L., Dubois, C., \& Faley, R. (2009). A case study analysis of factors that influence attrition rates in voluntary online training programs. International Journal on E-Learning, 8(3), 347-359.

21. Myers, M. P., \& Schiltz, P. M. (2012). Use of Elluminate in online teaching of statistics in the health sciences. Journal of Research in Innovative Teaching, 5(1), 53-62.

22. Park, J. (2007). Factors related to learner dropout in online learning. In F.M. Nafukho, T.H. Chermack \& C.M. Graham (Eds.), Proceedings of the 2007 Academy of Human Resource Development Annual Conference (pp. 25-1-25-8). Indianapolis, IN: AHRD.

23. Park, J.-H. \& Choi, H.J. (2009). Factors influencing adult learners' decision to drop out or persist in online learning. Educational Technology \& Society, 12, 207-217. 
24. Reinmann, G., \& Mandl, H. (2006). Unterrichten und Lernumgebungen gestalten. In A. Krapp \& B. Weidenmann (Eds.), Pädagogische Psychologie. Ein Lehrbuch (pp. 613-658). Weinheim: Beltz.

25. Richter, T., Naumann, J., \& Groeben, N. (2000). Attitudes toward the computer: Construct validation of an instrument with scales differentiated by content. Computers in Human Behavior, 16, 473-491.

26. Richter, T., Naumann, J., \& Horz, H. (2010). Eine revidierte Fassung des Inventars zur Computerbildung (INCOBI-R). Zeitschrift für Pädagogische Psychologie, 24(1), 23-37.

27. Rovai, A. P. (2003). In search of higher persistence rates in distance education online programs. The Internet \& Higher Education, 6(1), 1-16.

28. Rowntree, D. (1998). Teaching through self-instruction: How to develop open learning materials. London: Routledge.

29. Saadé, R. G., \& Kira, D. (2009). Computer anxiety in e-learning: The effect of computer selfefficacy. Journal of Information Technology Education, 8, 177-191.

30. Sam, H. K., Othman, A. E. A., \& Nordin, Z. S. (2005). Computer self-efficacy, computer anxiety, and attitudes toward the internet: A study among undergraduates in Unimas. Educational Technology \& Society, 8, 205-219.

31. Stiller, K. D. (2009). Mono- und bimodale Textpräsentationen zu Bildern in HypermediaSystemen. Psychologie in Erziehung und Unterricht, 56, 49-63.

32. Stiller, K. D. (2015). Linear vs. pictorial access to on-screen text and computer attitude. In S. Carliner, C. Fulford \& N. Ostashewski (Eds.), Proceedings of EdMedia: World Conference on Educational Media and Technology 2015 (pp. 158-167). Chesapeake, VA: AACE. Retrieved from http://www.editlib.org/p/151412/

33. Stiller, K. D., \& Bachmaier, R. (2014). NiceDesign4SME: A video-based online training course. In J. Viteli \& M. Leikomaa (Eds.), Proceedings of EdMedia: World Conference on Educational Media and Technology 2014 (pp. 373-383). Chesapeake, VA: AACE. Retrieved from http://www.editlib.org/p/147526

34. Sweller, J. (2010). Element interactivity and intrinsic, extraneous, and germane cognitive load. Educational Psychology Review, 22, 123-138.

35. Tinto, V. (1993). Leaving college: Rethinking the causes and cures of student attrition. Chicago: The University of Chicago Press.

36. Tyler-Smith, K. (2006). Early attrition among first time eLearners: A review of factors that contribute to drop-out, withdrawal and non-completion rates of adult learners undertaking eLearning programmes. Journal of Online Learning and Teaching, 2(2), 73-85.

37. U.S. Department of Education (2010). Evaluation of evidence-based practices in online learning: $A$ metaanalysis and review of online learning studies. Retrieved January 19, 2016, from http://www2.ed.gov/rschstat/eval/tech/evidence-based-practices/finalreport.pdf

38. Xenos, M., Pierrakeas, C., \& Pintelas, P. (2002). A survey on student dropout rates and dropout causes concerning the students in the course of informatics of the Hellenic Open University. Computers \& Education, 39(4), 361-377. 